\title{
Metropolitan Vision, Stakeholder Action and Community Involvement in Regeneration of Seaside Cities: Innovative Strategies from New York City for the Gulf of Naples
}

\author{
Massimo Clemente ${ }^{1, a}$ \\ ${ }^{1}$ Via Guglielmo San Felice $n^{\circ} 8$, Naples, Italy \\ am.clemente@irat.cnr.it
}

Keywords: Maritime Identity, Metropolitan Waterfront, Urban Regeneration, Public Participation.

\begin{abstract}
This paper suggests to reflect on the waterfront in a nontraditional way, referring to theoretical and methodological assumptions, developed in recent years about "Cities from the Sea" by our research group in the National Research Council of Italy. So the first step is to move from cognitive analysis to proposals and projects. We can refer to the positive experience of New York that is a best practice in approach, strategies and results.

The key of this success is a synthesis of the metropolitan vision favored by the public government, the activation of stakeholders to get results of common interest, the involvement of local communities. People was informed and motivated to put a position, they were encouraged to participate and to give a significant contribute to the achievement of results.
\end{abstract}

\section{Urban coastline issues}

The coast, close to the sea, is a sensitive area where the issue of sustainable development shows itself in all its complexity and potentiality. In urban and metropolitan areas, complexity increases as well as potentiality, at environmental, social and economic level. The coastline is a hinge area that is characterized by the biological diversity of two coastal habitats that join: the marine and terrestrial one.

At the present day, urban waterfronts are often affected by an high level of pollution, both inside and outside of the harbor. On the mainland, the coastal area is often densely built and it hosts residential and leisure functions as well as industrial settlements that cause a strong ecological footprint. Actually, also in other contexts where production activities are in a decreasing trend, we usually find a strong past pollution burden that makes very hard to recover and to reuse the area.

The enhancement of the waterfront must begin under the water to be effective, through the restoration of the marine habitat. At the same time, we must proceed with the clean-up and the remediation on the mainland, if necessary, when the coastal area had been used for industrial purposes.

On the social level, the metropolitan waterfront usually offers a good opportunity to realize public spaces that are very suited to facilitate aggregation of people and to improve social cohesion. The view over the sea is very important at psycho-perceptive level, because it opens the mind and promotes the socialization through a good disposition towards the other people. The creation of public spaces close to the sea has always generated positive impacts: promenades, meeting places, public parks and sports places. In addition, terminal and quays are spaces of mediation between port-cities that are connected by the maritime routes of the ships.

However, the creation of public spaces could produce concentration of people and of leisure functions so that it became a font of potential congestion on the waterfront. This should be prevented through a metropolitan vision of the urban life and activities, by managing functions, flows and mobility both at the physical level and at the immaterial one.

Anyway, the feasibility of the process of transformation of the waterfront is played on the economic front. This occurs for every recovery plan for redeveloping built areas close to the sea or to 
the rivers. Further, the economic evaluation must consider the remediation in the water and that one on the mainland through ex ante and ex post indicators.

The ability to produce economic added value through the intervention on the coastal zone is the prerequisite and, at the same time, it is the best indicator of feasibility for each project or proposal. Finally, the economic analysis is the tool to verify the impacts and the feedback helps us to modify and to enhance the project.

The theme of the waterfront has a very extensive scientific literature and, at the operational level, a sampling of projects that have been more or less successfully implemented in different regions and seas of the planet.

During the Fifties, the first harbor regeneration interventions took place in the United States of America, specifically in Baltimore [1, 2] and Boston [3].

In the first phase, port/docks and urban areas close to the sea had been transformed in different ways but always according to functional traditional approaches $[4,5,6,7,8,9,10,11,12]$.

Then, during the Nineties, public participation and awareness of environmental topics increased. Scholars - in particular geographers - proposed a wider approach $[13,14,15,16]$.

We can individuate a new trend starting on 2000 with attention to the maritime perspective and shared methodologies at an international level [17, 18, 19, 20, 21].

\section{Maritime identity for urban regeneration}

The maritime interpretation of seaside cities is a key issue for new approaches to urban regeneration of disused port areas and of coastal zones. We have studied the "maritimity" (maritime identity) as a fundamental tool to understand cities by the sea since 2009 . The objective is to deepen the relationship among sea and cities, port and ships, maritime history and urban form, sea routes and urban cultures.

We propose an innovative approach to the issue of recovery of the waterfront, which must be based on the identity of the maritime cities and of urban communities.

In our vision, the sea is considered as a primary element for regeneration of urban coastal area. The strategy is based on awareness and valorization of the maritime identity - this is the key of success of every project for regenerating the waterfronts [22, 23, 24].

The book "City from the sea. The art of sailing and the art of building the cities" was published in 2011 to illustrate the results of our research activity (original title: Città dal mare. L'arte di navigare $\mathrm{e}$ l'arte di costruire le città).

Specifically, it finalized the first phase of the project concerning with a methodology for multidisciplinary analysis of cities and architectures by the sea and, more generally, of coastal urban areas. This methodology has been verified through the application to four types of seaside city Mediterranean cities, cities of Northern Sea, Oceanic cities and river port cities - choosing three case studies for each type.

In the next phase (2011-2013) we focused on the strategic planning and the urban design in seaside cities through an aware maritime approach. We involved multidisciplinary scholars, stakeholders and policy makers on the case studies of Naples, Genoa, Trieste and Salerno. The conference "Sea and the city. Urban culture and maritime culture for the sustainable development of coastal urban areas" took place, in September 2012, to promote and to diffuse the research results.

The conference location was overlooking the Bay of Naples and actors were very different among them: scholars from multiple disciplines, marine biologists, naval engineers, architects, planners, designers, touristic operators, real estate developers, shipping companies, professional sailors, port authorities and politicians with specific responsibilities on coastal regions.

The third phase of the project is ongoing and it is focused on Naples city and its Gulf. We arranged the conference "Sea and the city 2.0. Participation and partnership for local sustainable development in Naples" in April 2014. The conference took place during the sail regattas of the World Series for 
the America's Cup - scholars, stakeholders and citizens debated very much about this sport event that had been expensive even if the impact on the city was very limited.

The problem is about which is the best way to valorize the maritime identity of Naples? How the urban community can enhance marine habitat and coastal environment? Which is the right strategy to promote economic growth based on the sea and on the maritime cluster? How the maritime culture can help to enhance the future of urban form and the future life of Naples citizens and city users?

Our aim was to debate with academics and researchers and over all to cooperate with technical and economical associations that are concerned with the transformation of the urban coast of the Bay of Naples. The objective has progressively moved from the port of Naples to the great metropolitan coast of Naples, from South to North: Capri, Sorrento and Amalfi peninsula, Vesuvius coast area, the city of Naples, Pozzuoli and Campi Flegrei, Ischia and Procida islands, Cuma, Licola and Castel Volturno.

\section{A new approach to the metropolitan waterfront: Naples meets New York City}

The vision should be at regional scale because the relationship with the sea cannot be considered with limited prospects. The sea is an open element as well as the contemporary metropolis - open towards the external.

The metropolitan vision of coastal development must be accompanied by the intervention at the neighborhood level. This must be carried out with the direct and active participation of local communities. For the implementation of the project is essential the contribution of the stakeholders and the planner must provide that the different interests converge - citizens, stakeholders, policy makers - only in this way the interventions on the waterfront will be successful.

A good practice comes from New York City where the waterfront has been the subject of important works of restoration and redevelopment that are still in progress [22, 23], [25]. The coastline of New York is $520 \mathrm{~km}$ long and it presents very different situations from environmental, social and economic points of view. We have the direct view on the ocean and on inland waters, we have beautiful beaches but also contaminated areas, we have intensive built neighborhoods but also great public parks. There is a good system connections on the waterways that joins the different parts of the metropolitan area of New York: Manhattan, Brooklyn, Queens, Bronx, Staten Island.

Many areas have been recovered in Manhattan: Street Seaport, Pier 17, Battery Park, Chelsea Piers and so on. At the present moment, the most interesting projects are developing in Brooklyn: Williamsburg Waterfront, Domino Sugar Factory, Brooklyn Bridge Park, Redhook and so on.

The key to success, in my opinion, is in three factors:

- the metropolitan vision of the theme of the waterfront that both the local administration and the citizens have;

- the focusing on the projects at neighborhood scale that have been concretely defined favoring the implementation;

- the ability to promote coalitions and alliances in order to obtain results of common interest without ideological foreclosures.

The metropolitan vision is very present in the New York best practice even if the transformation process of the urban waterfront assumes different forms and also the actors are multiple.

First we note a sense of identity that combines residents the five districts: Manhattan, Brooklyn, Staten Island, Bronx, Queens. Everyone feels the social identity of belonging to the metropolitan city of New York. It's to be stressed that the water helps to connect, physically and metaphorically, the five districts and its inhabitants.

Policy makers have a metropolitan vision of the problems and of the possible solutions, in agreement with the metropolitan community. The water is always present as a fundamental element in the vision and in the projects - the previous Mayor Bloomberg used to say that water is the sixth district of New York City. 
Finally, also economic operators have a metropolitan vision of the market potentialities that is composed by water and mainland. For example, this favors the synergy between the passenger shipping companies and the real estate developers.

In this metropolitan vision, projects are going ahead at the neighborhood scale through some circumscribed and right defined proposals. Private Citizens often present new projects and the institutions are allied with them to get the result - they aren't enemies that contrast the path. Certainly, there is the bureaucracy also in New York, but the negative impact is absolutely not comparable to what happens in Italy.

The planning proposal can come from institutions and from policy makers, but they usually activate the information process for involving the urban community. This helps to collect citizen consent and financial support from public and private investors. Furthermore, businessmen and real estate developers dialogue among them, with citizens, association and policy makers, in order to ensure the feasibility of their projects.

However, the key of the whole process is the ability to support individual projects through a strong and consolidated associations that collects energies for achieving the shared goals. In this scenery, the planner has also the role of facilitator and promoter. In fact, the plan also becomes an implementation program where the feasibility is guaranteed by the convergence of different interests.

The planner analyzes the idea, he defines the project following the guidelines of policy makers and evaluates the different stakeholders objectives. He identifies the areas of potential overlapping of expected results by the different actors. At the end, the planner finalizes the convergences of stakeholders, citizens and policy makers, to realize the plan previsions.

The right balance - between the metropolitan vision action and at the neighborhood level - is made explicit in two best practices proposed in the following boxes.

The first is a good practice to create a deep and shared vision of the waterfront at regional scale, developed and promoted by the Metropolitan Waterfront Alliance. (Fig 1) The second box is about the experience of the redevelopment of the Chelsea Piers that of great importance for the active participation of different stakeholders involved. (Fig. 2)

Both the boxes have been articulated through the same scheme: History - Aims Project - The goal of this experiment.

The question is whether the New York model could be transferred to Naples and its surrounding. The objective is to favor the sustainable regeneration of the metropolitan coast through the alliance of all the subjects that can be involved. At first examination Naples and New York are cities very different but an historical reading helps us to see the similarities. Naples was one of the most multicultural cities in the eighteenth century as well as New York is one of the most global cities in our contemporary multicultural world.

Geographically, even though both the cities are located on the $41^{\circ}$ parallel, climatic conditions are very different: Napoli has a mild Mediterranean climate, while New York has very cold winters and is exposed to hurricanes.

Quite different is the size: New York is a metropolitan city of over 8 million people on $800 \mathrm{kmq}$ compared with about 3 million people on $1200 \mathrm{kmq}$ in the metropolitan area Naples.

If New York City has the metropolitan government that is articulated in five boroughs, Naples hasn't yet a real metropolitan government neither a metropolitan governance.

Vulnerability and resilience can be identified as common factors. Naples is located in a high risk volcanic area with the presence of the active volcano Mount Vesuvius. In New York there isn't a geological or volcanic risk but the hurricanes are a real hazard and they can cause serious damage as it happened with the Hurricane Sandy. The stories of Naples and New York show the resilience of the two cities - the ability to resist and react to crisis situations.

The biggest difference is the presence of strong associative movements for getting common goals that is at the basis of the American society. This associative soul isn't present in Neapolitan society that is very divided and un-willing to join efforts, probably for historical and anthropological reasons. 
Certainly this is a major obstacle for the application of the New York model in Naples but it isn't insurmountable.

\section{Box 1 - \\ Metropolitan Waterfront Alliance}

(Gaia Daldanise)

History: The Metropolitan Waterfont Alliance (MWA) is an alliance of over 600 organizations (enterprises, civic organizations, neighborhood groups, trade unions, local authorities, exc.). They are working together in order to transform water and waterfont of New York and New Jersey Harbor in a clean and accessible space. The aim is to maintain - both in short and long terms - a balance between urban growth and life quality on a sustainable basis, involving various stakeholders. The tools are the creation of green belts that run along the quays and act as a natural barrier between the landscape and the buildings, structures meant to be meeting places, and new job opportunities, as well as eco - friendly transports, reliable for all. In the many organizations that constitute the Task Forces MWA expert and non-experts know ledge are able to integrate and communicate at the same level (the ferry captains and environmentalists learn to communicate with the city-planners, canoeists discuss with the transport managers and so on). All this has resulted in a project aimed at promoting socio-cultural-economic ecological instances, that are understood and listened by decision-makers in government. In 2011 , as a very important achievement for the $\mathrm{MW}$, these extensive port strategies have been adopted by Bloomberg administration to become the vision for New York 2020: the complete Waterfont Plan for New York City. This is MWA: there a dynamic balance between heterogeneous and conflicting polarities (the different actors committed to the redevelopment of the waterfont) becomes the basic element for concrete proposals, addressed to the direct users of the port and waterways in New York: citizens [26].

Project Aims: The Metropolitan Waterfront Alliance is expected that the Port of New York and New Jersey recovers the "sense of place", vitality and creativity, redeveloping blighted areas, reconstructing proper connections between the sea and the city and reactivating maritime tourism (where sailboats, kayals and pleasure crafts would cut through waterways alongside commuter ferries, barges and container ships). This way, the Port of New York and New Jersey becomes a place for a wider network of waterfront destinations, each one with its own peculiar characteris tics that make it a unique statement for a part of that specific area. The beauty of the waterfronts' diversity makes them a valuable resource, available to all. Actually, this "user-centered" approach is the aim and, at the same time, a successful strategy of the MWA. Its mission is to create a connection that is able to structure the city in relation with green, paths, w aterw ays and waterfront. It starts from a bottom-up approach that is aimed at solving the most complex systems on a regional and urban scale, from the individuality of the users' individual needs. Starting point is the redefinition of the port and its landscape quality and how they are perceived by different actors.

The goal of this experiment: Planning its actions, the MWA paid particular attention to the social aspects and cohesion, creating opportunities for interaction between various stakeholders through conferences, forum and focus groups. At the same time realized physical places for aggregation and cultural exchange (A Waterfont Town, A Well Designed Edge). On the environmental and ecological side, particular emphasis w as given to the reconstruction of biodiversity along rivers, streams, canals and bays, as well as the decrease of water pollution (A Green Harbor). Moreover, ecologically was conceived a policy in order to reduce overall air pollution thanks to sea transport, such as barges that become valuable alternatives for the public transport of goods and people (Blve Highways). From the economic point of view, new job opportunities and occasions of development have been identified, encouraging the increase of the shipping, touristic and hospitality industry (A Working Waterfront). In particular, the Waterfont Action Agenda of the MWA includes well-defined actions, as from the following model on the right side.

The model built and made real by the MWA appears to be a pilot intervention of redevelopment of the waterfont in the 21 st century, as promoter of sustainable development among the community, in the community and for the community.

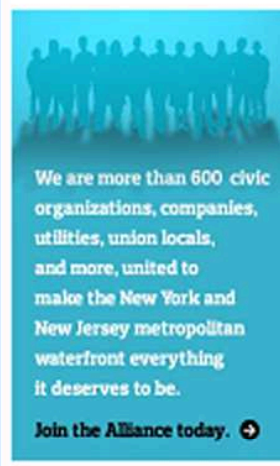




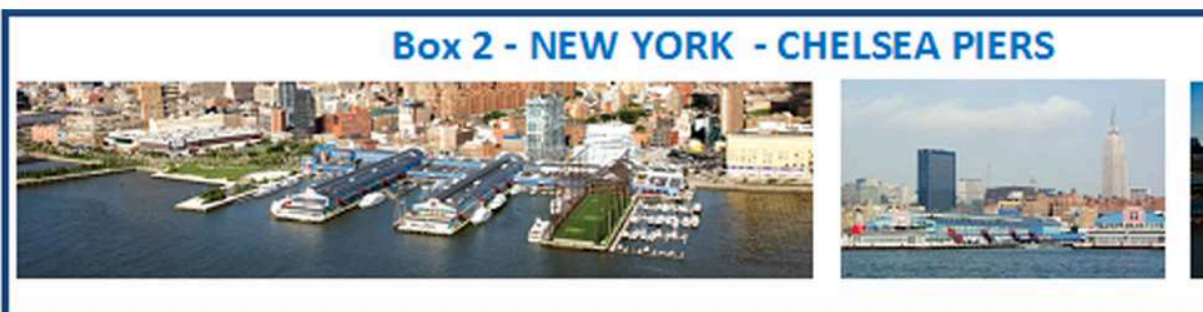

History: The history of the Chelsea Piers, of the eight Piers ranging from 54 to 62 , beginning in the second half of the XIX century when the architects Whitney Warren and Charles D. Wetmore realized a terminal for transoceanic ships. The birth of the Chelsea Piers was, at first, very hard. At the end of the XIX century the increasing size of transoceanic ships led to the creation of a terminal for the passenger ships. The work's enlargement lasted from 1910 until the $60 \mathrm{~s}$, changing the face of the port of New York, which offered a shelter for the largest ships in the world. In 1970 beginning the slow decline of the area, with a new redevelopment project that had the aim to build a new highway. But this project declined and, in 1992, the new company Chelse a Piers Management acquired the properties of the four piers remained, from n. 59 to 62 , as part of a public project doomed to redevelop the whole sport's area. In 1995, the Chelsea Piers have become the biggest and most important sports complex in New York, promoting the following activities: golf, swimming, surfing, athletics, fitness, tennis and hockey. The pier 59, where would have to moor the Titanic, is now the place where there are many recreational activities for leisure. The Chelsea Piers before the redevelopment project w as completely ab andoned, a waterfont totally degraded, which had denied the great past of this place. The structures were almost collapsing, industrial archeology was exposed to the winds of the Hudson River [27].

Project Aims: The redevelopment project of Chelsea Pier has been an initiative of public and private interest. The goal was to transform the whole area into an open park, which recognizes the history of place and draw to preserve it and pass it on to future generations [28]. In May of 1992, after six months of research to prepare a detailed proposal, a newly formed company, Chelsea Piers Management Inc., has submitted a proposal to the Department of Transportation of New York to manage the redevelopment of the Chelsea Piers. As the years go this company grows, and was born a real team, which in 24 months has defined a program to redesign the waterfont. The aim of this project is to make the requalification of the waterfront a good practice in the world following the Green Economy principles. So has been promoted the reduction of pollution, the use of renewable energy, reuse and recycling.

The goal of this experiment: The success of this experience has been the participation of local associations: Chelsea Group, Community Board 4, The Greenwich Village Chelsea Chamber of Commerce, the Friends of the High Line, and the 23rd Street Association. The citizens show a strong interest for this project: the idea of giving back to the city a place of considerable landscape valve has stimulated all stakeholders and has encouraged the entrepreneurs to believe in this initiative, financing it [29]. Initially, local govemment authorities don't believed in this project, for lack of funds, but the work began in 1994, with the celebration of the first stone that saw personally involved Mayor W. Givliani. This initiative generated the public interest, with the participation of 1200 people. In August 1995, The Chelsea Piers Sports and Entertainment Complex are open to the public. After this success begins the redevelopment of a second area, the Chelsea Piers Connecticut in Stamford, Connecticut. We are talking about 400,000 square meters dedicated to the sport which develop more than 20 different sports activities. Were realized outdoor parks and green streets. The birth of the water taxi was a great invention bec ause reduced the time required to cross the city. The goal was to promote contimous public participation events to give credibility to the project, involving the local government and using the relationship with the press was a good strategies to make know $n$ the initiatives .
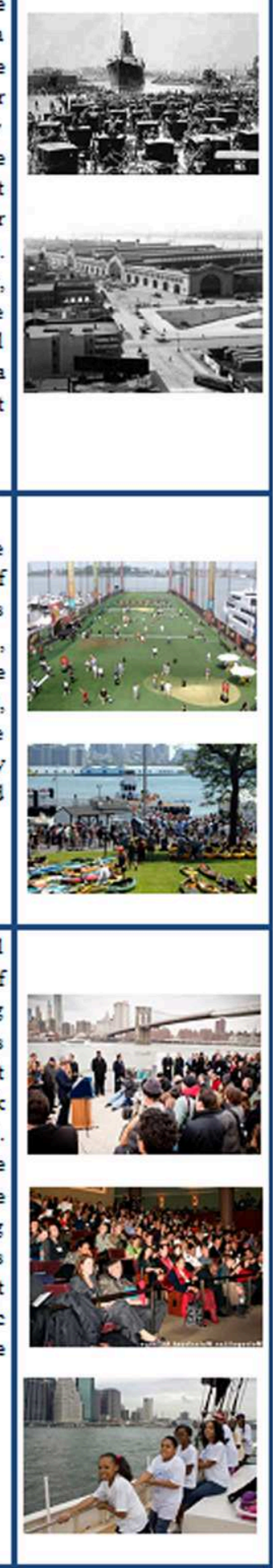

Fig. 2 The Chelsea Piers on the Hudson River are a good practice of convergence of public and private interests. 


\section{Conclusion}

Naples has to go beyond the municipal logic especially through the community base action, aiming at a metropolitan vision even without an institutional interlocutor. Actually-despite in Italy there has been a prescription of law since 1990 to introduce the metropolitan cities as a form of intermediate government - there isn't yet an official institution for the government of the metropolitan city of Naples as well as of Rome or Milan. Waiting for the metropolitan government, we should begin to promote the metropolitan community, the Latin "civitas" based on a strong identity sense at the metropolitan scale.

The redevelopment and enhancement of the metropolitan coast may be the point of convergence of multiple interests. The objective is triggering a process based on the maritime awareness and aimed to sustainable development through project-proposals and implementation plans.

The model of the Metropolitan Waterfront Alliance can be imported in Italy and specifically in Naples. It should be launched at the regional scale, considering the whole Gulf of Naples, coast and islands, although if contexts are very different from the environmental, social and economic side, if compared to New York City.

The strategy must combine a general perspective with the capacity to focus on specific projects. The objective is a metropolitan vision which, however, must be implemented through local projects that start from the bottom, or that are otherwise shared by most of the stakeholders, the local community and the policy makers. The challenge is to join together all the stakeholders in a common project: citizens and city users, government and the governance system, consumers and the productive system.

Naples could have a Metropolitan Coast Alliance that should be inspired to the Metropolitan Waterfront Alliance of New York City, of course with the necessary modification related to the different context. The richness is right in the variety of the built environment along the coastline as well as the variety of the landscape and of the marine habitat, in the Gulf of Naples as well as in the Bay of New York, the Hudson and the East River. The process could start from the scientific community and involve progressively all the subjects of the metropolitan coast of Naples.

\section{Acknowledgements}

The paper is a work in progress of the research project "Urban strategies for contemporary city: multiculturalism, identity, recovery and valorization", coordinated by Massimo Clemente, funded by National Research Council of Italy (CNR), Institute for Service Industry Research (IRAT). Thanks to Gaia Daldanise (PhD candidate) for Box 1 and Mariarosaria Angrisano (PhD candidate) for Box 2.

\section{References}

[1] Baltimore County Waterfront Recreation Survey, Department of recreation and Parks, Office of planning and zoning, Baltimore County (1959)

[2] D. A. Wallace: Urban planning my way: from Baltimore's inner harbor to Lower Manhattan and beyond, Planners Press, Chicago (2004)

[3] Boston Redevelopment Authority Downtown waterfront, Faneuil Hall urban renewal plan. (draft) Downtown Waterfront Corporation, Boston (1964)

[4] M. L. Moss: The Urban Port: A Hidden Resource for the City and the Coastal Zone. Coastal Zone Management Journal, Vol. 2, (1976), n. 3

[5] Committee on Urban Waterfront Lands: Urban Waterfront Lands, Environmental Studies Board, Commission on Natural Resources, National Research Council, National Academy of Sciences, Washington D.C. (1980) 
[6] B. S. Hoyle, D. A. Pinder and M. S. Husain: Revitalising the Waterfront: International Dimensions of Dockland Redevelopment, Belhaven Press, London (1988)

[7] D. M. Wrenn: Urban Waterfront Development, Urban Land Institute, Washington D.C. (1983)

[8] P. G. Hall: Waterfronts: A New Urban Frontier, University of California, Berkeley (1991)

[9] A. Breen and D. Rigby: The new waterfront. A worldwide urban success story, Thames \& Hudson editions, London (1996)

[10] D. L. Gordon: A Planning, Design and Managing Change in Urban Waterfront Redevelopment, The Town (1996)

[11] P. Malone: City, Capital and Water, London and New York, Routledge (1996)

[12] H. Meyer: City and Port: Urban Planning as a Cultural Venture in London, Barcelona, New York, and Rotterdam: Changing Relations between Public Urban Space and Large-scale Infrastructure, International Books, Utrecht (1999)

[13] A. Vallega: Urban waterfront facing integrated coastal management. Ocean\& Coastal Management, Vol. 44, (2001), issues 5-6, pp. 379-410

[14] B.S. Hoyle: Cityports, Coastal Zones and Regional Change: International Perspectives on Planning (1996)

[15] R. Billé: Integrated coastal zone management: four entrenched illusions. S.A.P.I.EN.S Vol. 5 (2008), n. $387-404$

[16] D. R. Green: Coastal zone management, Thomas Telford, London (2010)

[17] R. Marshall: Waterfronts in Post Industrial Cities, Spon, London 2001)

[18] K. Dovey: Fluid city: transforming Melbourne's urban waterfront, University of New South Wales Press, New York (2005)

[19] R. Bruttomesso: Città porto - City port. Catalogue of the section of the 10th International Architecture Exhibition, La Biennale di Venezia, Palermo, 2006-2007, Marsilio Editori, Venezia (2006)

[20] P.H. Brown: America's waterfront revival: port authorities and urban redevelopment, University of Pennsylvania Press, Philadelphia (2009)

[21] G. Desfor, J. Laidley, D. Schubert and Q. Stevens: Transforming Urban Waterfronts: Fixity and Flow, Taylor and Francis Group, London (2010)

[22] M. Clemente: Città dal mare. L'arte di navigare e l'arte di costruire le città, Editoriale Scientifica, Napoli (2011)

[23] M. Clemente and E. Giovene di Girasole, in: Proceedings of Ambivalent Landscapes. Sorting out the present by designing the future, Public Spaces - Urban Cultures Conference, edited by S. Morgado and J.R. Santos, Lisboa (2012)

[24] M. Clemente: Il mare e la città. Tria, Vol. 11,(2013), pp.19-34

[25] E. Giovene di Girasole, M. Clemente and D. Demarco: Rigenerazione delle città dal mare per una crescita sostenibile. The Journal of Urbanism, Vol. 2, 27 (2013)

[26] Information on http://www.waterfrontalliance.org 
[27] Information on http://www.chelseapiers.com

[28] L. Fusco Girard and P. Nijkamp: Le valutazioni per lo sviluppo sostenibile della città e del territorio, Franco Angeli, Milano (2003)

[29] L. Fusco Girard and P. Nijkamp: Energia, bellezza e partecipazione: la sfida della sostenibilità. Valutazioni integrate tra conservazione e sviluppo, Franco Angeli Edizioni, Milano (2005) 